\title{
إشكالية الشكل والمضمون في فلسفة هيجل الجمالية
}

\author{
د. فيصل بشير الحخاز \\ كلية الآداب / جامعة مصراتة
}

مقدمة

يعتبر هيجل من الفلاسفة العظام إبان عصره وتعتبر فلسفته من الأعمال الفلسفية

الكبيرة الواسعة الأفق، وكان من الذين ثاروا على النظريات الاقتصادية الماركسية وأرسوا دعائم

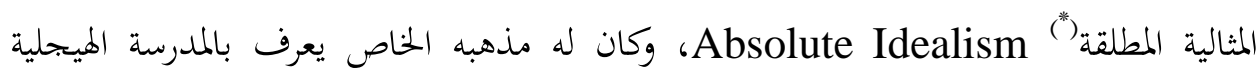
وتبعه ظهور أتباع التيار الهيجلي، وبالتالي كان ابتحه هيجل ميتافيزيقياً في عرضه لمذهبه الجمالي حيث بدأ بحثه في الفكر والمثال وتفسير إشكالية الشكل والمضمون في الأعمال الفنية، وطرح نظريته من خلال الأنماط الثلاثة الرئيسية التي فسر بها تطور الفن عبر الحضارات الإنسانية المتعاقبة، وقدم خصائص الفنون الجميلة وبين رؤيته الواسعة وإحساسه العالي في تذوق الفنون ووضح مهمة الفن الرفيع في التعبير عن الروح المطلق، والأكثر من ذلك عرضه الدور الفعال الذي يقدمه الفن في خدمة العقائد الدينية والطقوس السحرية وبحسيد الأسطورة، وبالتالي التوصل إلى العلاقة الجحلية التي تربط ما بين الفن والدين الفلسفة واعتبارها مظهراً للروح المطلق.

إشكالية البحث:

تأتي إشكالية البحث من خلال رؤية هيجل الجمالية بأن مهمة الفن في التعبير عن

الروح المطلق، وارتباط الفن بالدين والفلسفة حينما اعتبر أغها مظهر للروح المطلق وإن الجمال الطبيعي ما هو إلا خطوة أولية نحو الجمال الحقيقي وهو الجمال الفني الذي يجسد رؤية جديدة

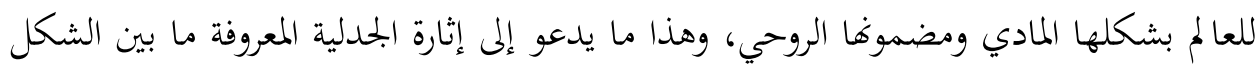
والمضمون في الأعمال الفنية من خحلال نظرية المحاكاة والميثولوجيا، ولمعرفة مدى التفاوت ما بين 
الذاتية والموضوعية وما بين الروح والمادة وفقاً للأنماط الثلاثة الرئيسية في الفن بحسب رؤية

لاشك أن دراسة هيجل الجمالية عن تاريخ الفن وتصنيفاته للفنون الجميلة هي بمثابة

موسوعة قيمة تساعدنا في التعرف على تاريخية الفنون الأوروبية المعاصرة... وبالتالي فإنه من

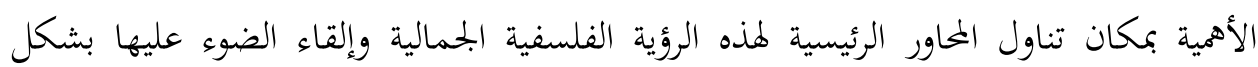
موجز من خلال هذا البحث؛ مما يتيح للقارئ العادي والمختص الإحاطة بما يحمله فكر هذا الفيلسوف الفذ من رؤية بديعة وخلاقة في هذا البمال.... ومن هنا تكمن أهمية هذا البحث... وقد توخيت في هذا العرض اتباع المنهجية التاريخية التحليلية واللجوء إلى المقارنة في

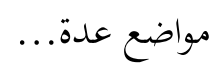

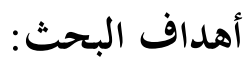

تقديم دراسة موجزة عن الجوانب الأكثر أهمية في فلسفة هيجل.

تسليط الضوء على أهم المحاور الأساسية التي قدمها في تفسير الظاهرة الجمالية وتناوله لنظرية المحاكاة ومفهوم الأسطورة وعلاقتها بالفن. مشكلة الشكل والمضمون من أهم القضايا الفلسفية في الفن التي تناوها فلاسفة الجمال وكانت مثاراً للجدل والاختلاف فيما بينهم وقدموا رؤاهم ونظرياهم كلهّ حسب فلسفته ومذهبه الخاص أو المدرسة التي يتبعها.

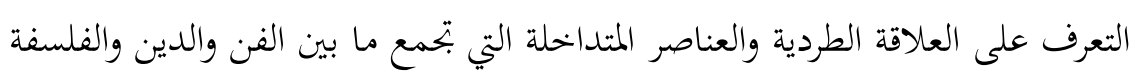
وفقاً لمنهج المدرسة الهيجلية. محاولة لتقديم رؤية جديدة وموجزة لفلسفة الفن والجمال عند هيجل وتناولها من زوايا مختلفة لما سبق عرضه. 
يعد هجيل من أعظم من تناولوا مشكلة علم الجمال والفن في العصر الحديث، وكان

مذهبه الجمالي بداية عهد جديد للانطلاق الروحي الميتافيزيقي في الفن باعتباره فكرة.

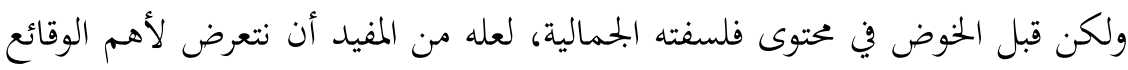

والمعطات في حياة هذا الفيلسوف والتي كان لها تأثير على توجهاته وآراءه الفلسفية.

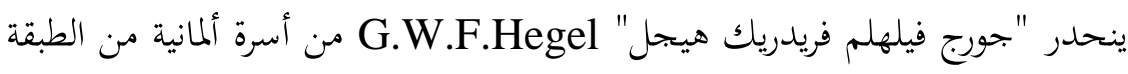

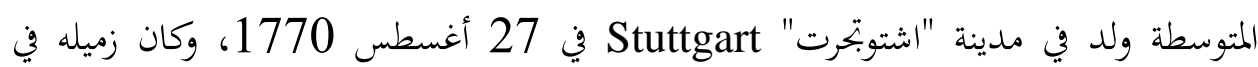

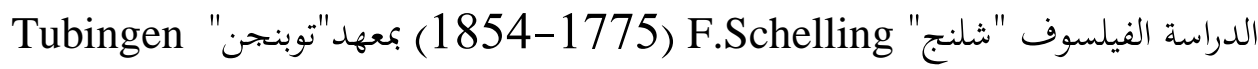
توكان Institute

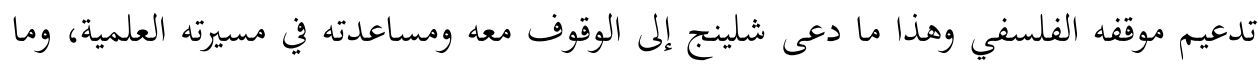

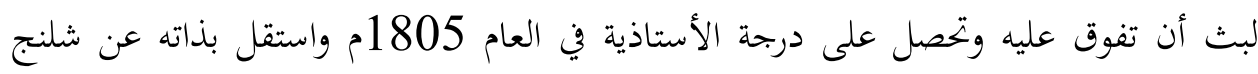

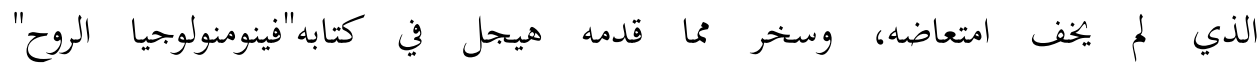
Phenomenology of Spirit

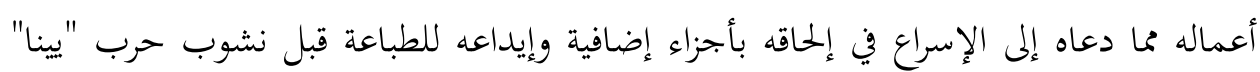
(1) عام Jena بعد الحرب رحل إلى جنوب ألمانيا، وعاش في نورنبرغ مurnberg ثماني سنوات، ثماتماني

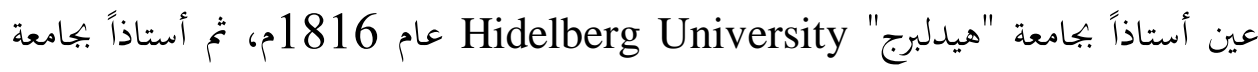

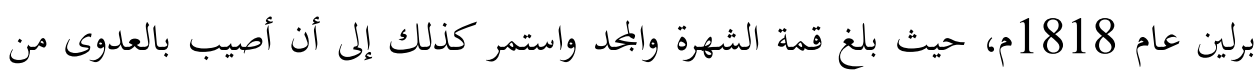

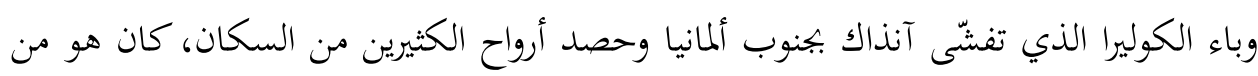

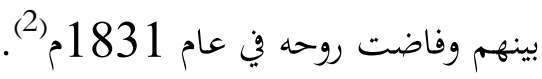




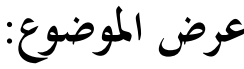

فلسفة الفن عند هيجل تعتبر حلقة في مذهبه الفلسفي العام كمثال الدين والتاريخ

فالروح المطلق Absolute Spirit في ابتحاهها إلى المثل العليا، فيتجه إلى الجمال وإلى الحقيقة

وإلى الألوهية فيفسر ابتحاهها هذا من الفن والفلسفة والدين (3).

والجمال عند هيجل هو التجلي المحسوس للفكرة، حيث إن مضمون الفن هو الفكرة،

أما صورته فتتلخص في تصويرها المحسوس والخيالي؛ ولكي يتداخل هذان العنصران يتوجب تحويل

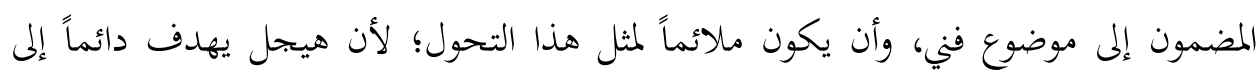
البحث في التعقيل الباطني في كل موضوع واقعي، ومع ذلك لا يمكن أن يظل فكرًا بحردًا، ويرى

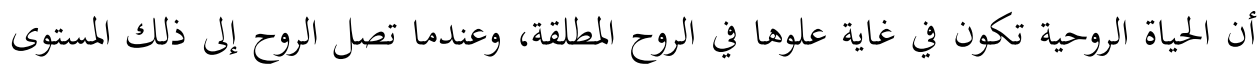
المتعالي فإها تتجلى في شعور واعِ بمثابة الموضوع الواقعي للفكرة أو العقل المطلق لكل الأشياء (4). ويرى هيجل أنه إذا بلغ الجمال غايته القصوى فإنه يشترك مع الدين والحياة في تفسير العنصر الإلهي وأيضاً ما يتعلق بالمطالب الإنسانية العميقة، أي ما يتعلق بحقائق الروح والأفكار

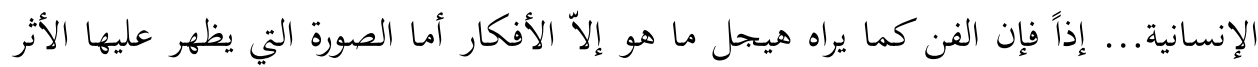
الفني فإها تستمد تكوينها من المحسوسات والخيالات، والعمل الفني ما هو إلا بتسيد أو لقاء

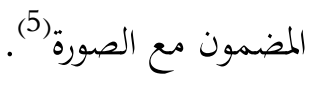

وبالتالي يخلص هيجل، إلى أن الفن حسب مذهبه هو وضع الفكرة والمضمون في مادة

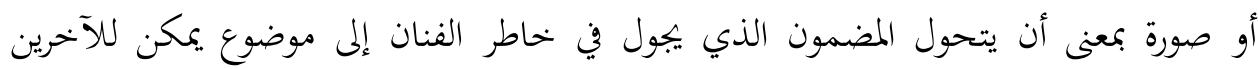
مشاهدته والإطلاع عليه، أو سماعه ولكي يتحقق ذلك يتوجب أن يكون هذا المضمون قابلاً لأن يظهر أو يتكون في شكل مادي على هيئة بحسم أو صورة أو صوت. ومن هنا بحد أن الفن عند هيجل يهدف إلى إظهار الدلالة الداخلية للواقع في أشكال

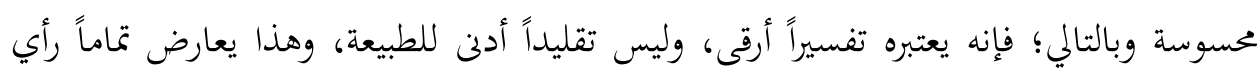
أفلاطون (427-347) الذي يعتبر الفن تقليد لا فائدة مرجوة منه. 
ولكن بحد من جانب آخر يتفق هيجل مع أرسطو (384-322ق .م) في أن الفن له دور إيجابي في تطهير النفس من الانفعالات السلبية وله تأثيرات أخلاقية إيجابية، كما أن له دور فعال في إيصال المعرفة والحقيقة بأسلوب مميز يمكنه النفاذ إلى المشاعر الإنسانية على شكل أشياء عينية بجسمة أو مصورة وحتى مسموعة دون الحاجة إلى اللجوء للوسائل التعليمية التقليدية أو لتحقيق مكاسب مادية للوصول إلى المعرفة.

وقد ركز هيجل على الجحانب المعريف في الفن باعتباره التجلي المحسوس للمطلق وهو

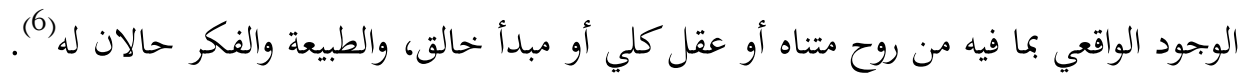
وبحسب هيجل فإن الإنسان يخلق صوراً من الجمال تكون أكثر تعبيراً مما هو موجود في

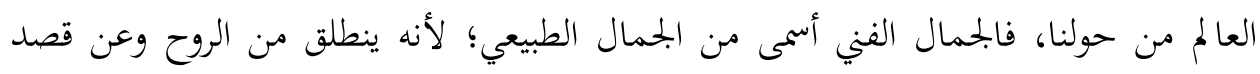

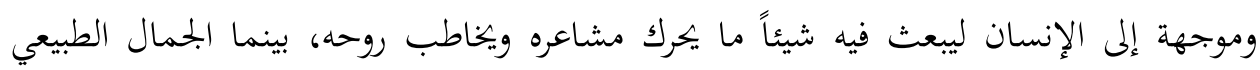
يظل صامتاً يخلو من الفكرة والمضمون وبالتالي ليس هناك ما يبعث به إلى إلى الروح والإنسانية وليس من ورائه مقاصد بشرية يمكن استخلاصها. كما قدم هيجل دراسة وضح من خلالها مراحل ظهور الجمال وهي عبارة عن

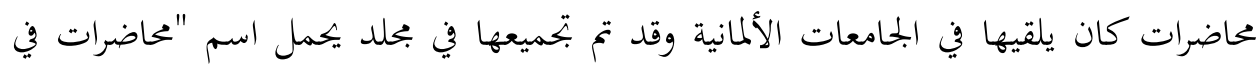
فلسفة الفن الجميل"، ولعل أهم ما يمكن الإشارة إليه هو رؤيته أن علم الجمال هو فلسفة الفن

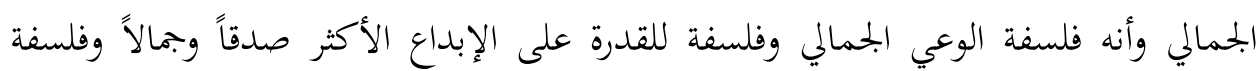
للتذوق الأكثر قدرةً على الاستيعاب(7)، والذي عن طريقه يمكن معرفة وتحديد الفنون الجمميلة

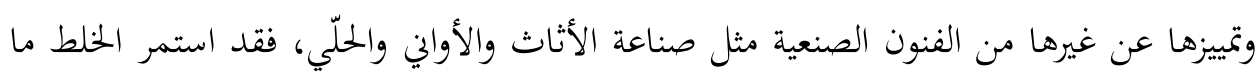
بين الفنون الجميلة والفنون التطبيقية منذ العهد اليوناني القديم، فكان أرسطو يعتبر الفن مساوياً

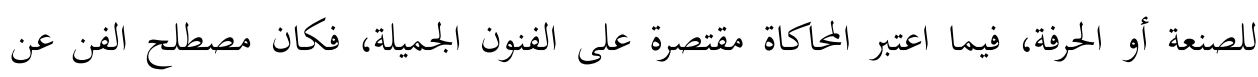
اليونان القديم هو Techne ويطلق على النشاط الصناعي وما يقابلها من الصناعات المهنية

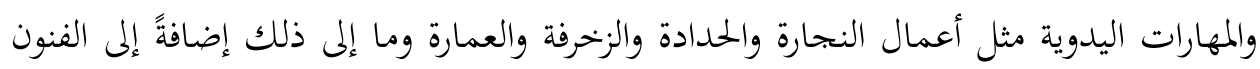
الاعتيادية مثل النحت والرسم، والموسيقى وغيرها من الفنون الجميلة المماثلة(8). 
وين العصر الحديث فإن اليونانيين اشتقوا المصطلح Technology واقتصر استعماله لتوصيف التقنية الصناعية، كما اشتق المصطلح اللاتيني Art واقتصر استعماله في تسمية الفنون الجميلة المتخصصة مثل النحت والرسم والموسيقى وما شابه(9).

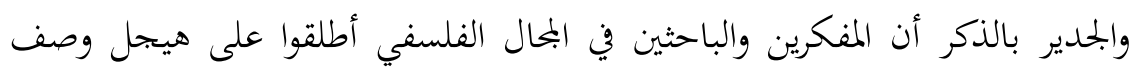
أرسطو العصر الحديث كونه استلهم فلسفته وأفكاره ممن سبقوه من الفلاسفة الكبار فقد استوعب ما سبقه من آراء وأفكار ونظريات الفلاسفة السابقين عليه وعرضها في محاورات جدلية بل إلى حد نقدها وتعديلها ابتداءً من أفلاطون وحتى كانط (1724-1804) ويعيد بناء

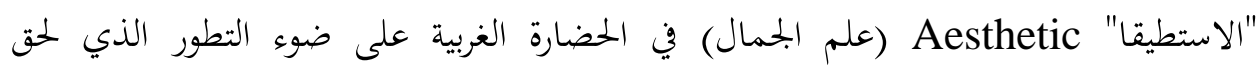
بالحضارة الأوروبية، وبالتالي قدم آراهه وأفكاره بشكل جديد متطور أثرت في مسار اللاحقين له

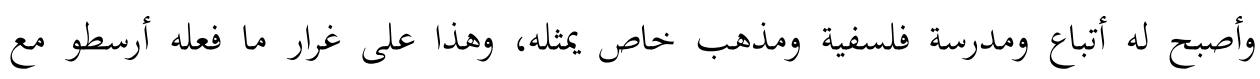

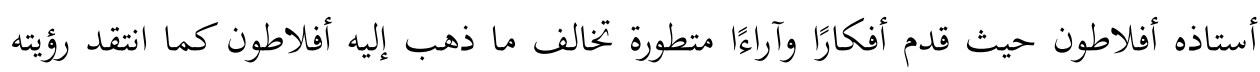

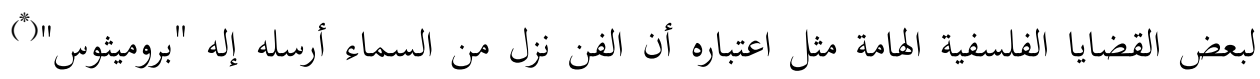

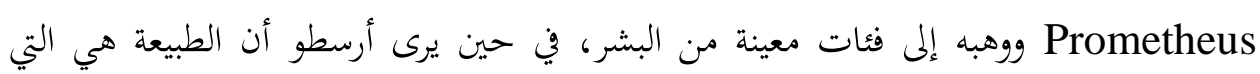
أعطت الإنسان اليد والإلمام لإبداع الفنون بمختلف أشكالها ما يضفي على الطبيعة جمالاً روحياً، ويبدها من طبيعة صامتة إلى محاكاة تنبض بالمشاعر والمعاني الإنسانية.

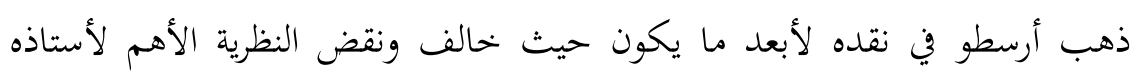

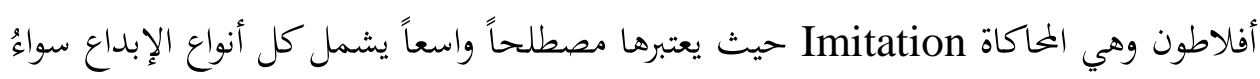
الإبداع العقلي والإبداع الفلسفي والإبداع الفني، في حين اعتبر أرسطو أن فكرة المحاكاة تخص

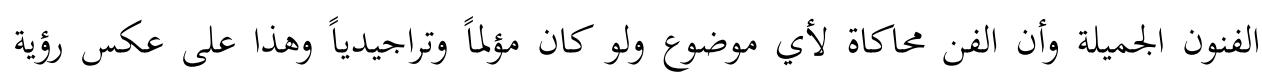
أفلاطون الذي يعتبره محاكاة للجمال المثالي(10). وقام أرسطو في كتابه "فن الشعر" Art of Poetry بتحديد مهاهمة الفن في المحاكاة، واعتبر أن المأساة هي محاكاة فعل وليس بحرد مطابقته في التقليد، ويرجع أرسطو أصل التراجيديا 
إلى شعر "الديثرامب" Dithyrambos")، وأما الملهاة "الكوميديا" إلى الأغاني الشعبية القديمة (11).

وهذا العرض للمواقف المتناقضة بين أهم فلاسفة اليونان القديم في تحديد مفهوم

المحاكاة يدعونا إلى التساؤل عن موقف ورؤية فيلسوفنا هيجل في هذا الشأن.

\section{المحاكاة في فلسفة هيجل الجمالية:}

حدد هيجل نظرية المحاكاة في الفن باعتبار أن هدف الفن وليهن ومهمته هي محاكاة الطبيعية

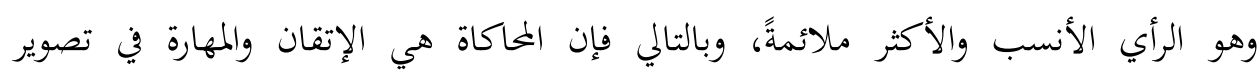

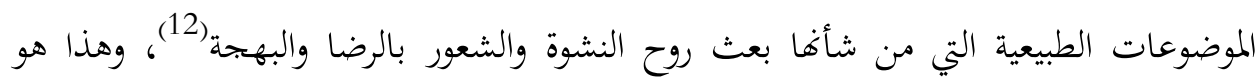

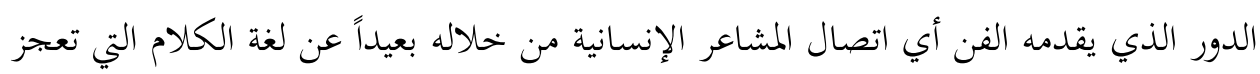
عن التعبير الكامل والمثالي عن الذات البشرية.

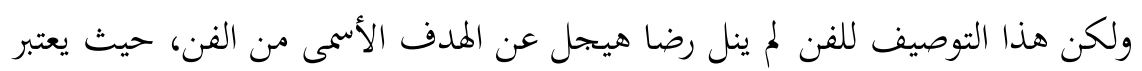

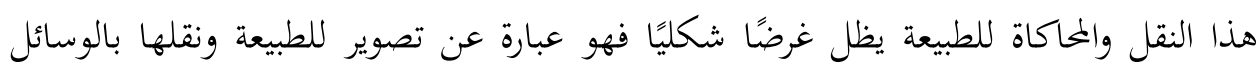

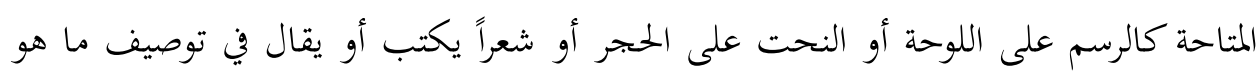

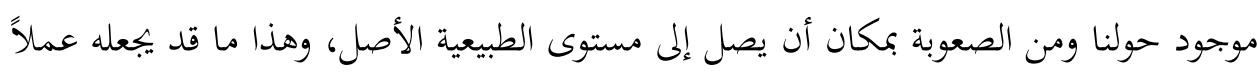

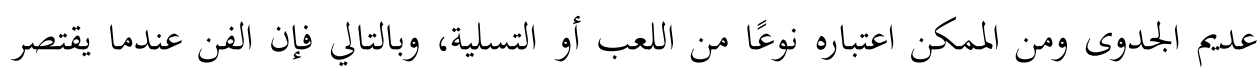

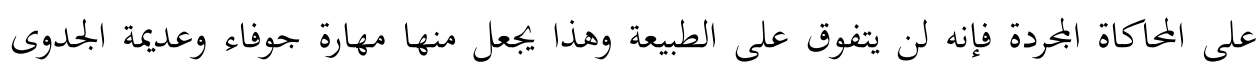
وبدون معنى أي خالية من المضمون.

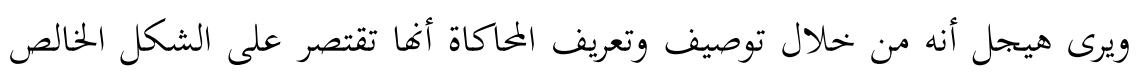

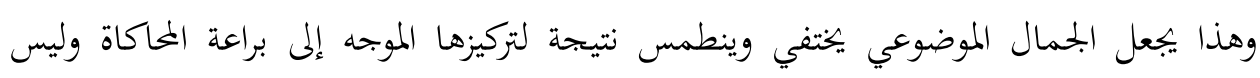

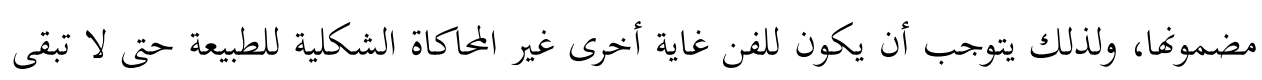

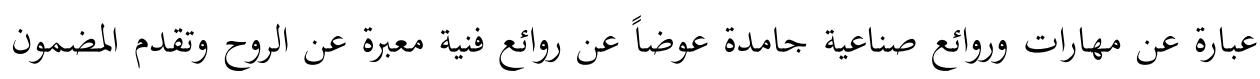

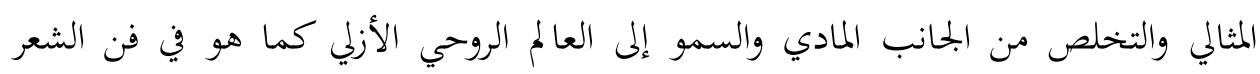
والموسيقى. 
ولعل هذا التوصيف يذكرنا بالموقف السلبي والمتشدد الذي اتخذه أفلاطون باعتباره صاحب نظرية المحاكاة ومبتدعها والتي ظلت المحور الأساسي لمفهومه الجمالي، فهو لا يعطي بلي

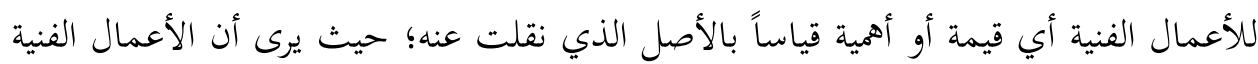
ما هي إلا محاكاة وتقليد للواقع والعالم الحسي المحيط بها(13)، وهذا يعطي صورة سطحية للعالم وييجعل منها أشبه بالظلال للواقع وفي مرتبة أدنى منه، وهذا الواقع وهذه الموجودات في العالم الحقيقي والماثلة أمامنا ما هي إلا تقليد وظلال لذلك العالم الأصلي الموجود في عالم المثل،

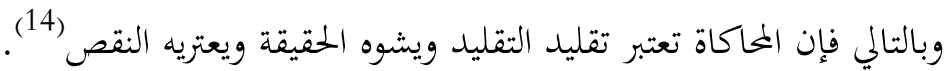
وبذلك فإن أفلاطون يعتبر الفن تزييف للحقيقة وتشويه للواقع وهذا يسري على فن الشعر والخطابة من خلال تمجيد الأشخاص والحكام وأيضاً فنون الرسم والنحت والتمثيل والغناء وما إلى ذلك، وعلى الرغم من مواقفه المتعارضة مع الفن إلا أن أفكاره وآراءه عن كون الفن محاكاة للجميل كان لها دور فعال وجوهري في تطوير مفهوم الجمال.

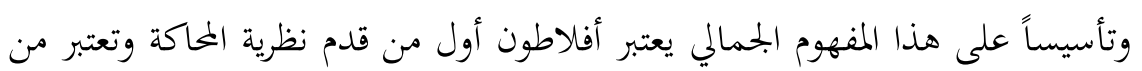

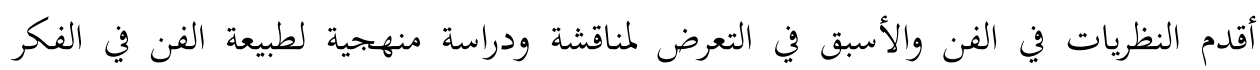

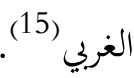
وبالتالي يمكن القول أن أفلاطون هو من أرسى دعائم ابتاه أصيل في الفن استمر يتناقله مداولة ما بين ناقد ومفسر وبحدد ما تلاه من فلاسفة ومفكرين على مرّ الحقب التاريخية وحتى العصر الحديث وإلى التاريخ المعاصر، ومن ذلك ظهرت آثاره على أكبر وأهم المدارس

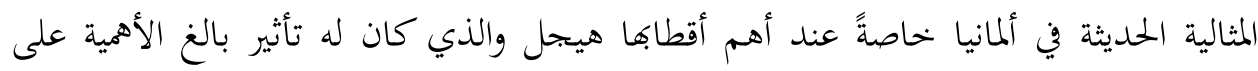
جيل من الفلاسفة الذين عاصروه أو جاءوا من بعده أمثال هوتو H.G. Hotho

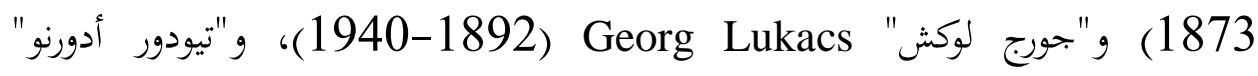
H.Bergson Theodor Adoron (1941-1859) وكروتشه B.Croce) (1956-1866) وآخرين لا يتسع المجال 
والجدير بالذكر أن هيجل ذو شخصية مميزة وغير اعتيادية في كثير من توجهاته وأفكاره

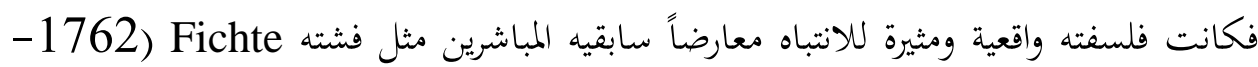
1814) بفلسفته المبشرة وكذلك شلنج chelling بأسلوبه الذي يتسم بالشطحات الشكلية

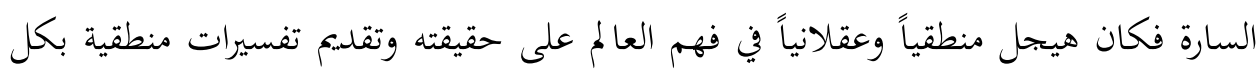

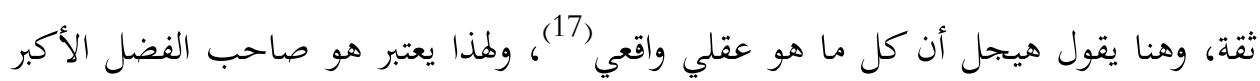
في ظهور علم الجمال بصورة جديدة وساد التيار المثالي فلسفة الفن الألماني من بعده. فقد تأثر هيجل بفلسفة "كانط" وجعل منها نقطة البداية له فقام بدراستها والتمعن

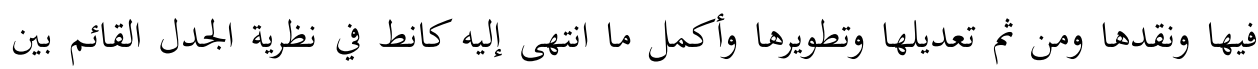

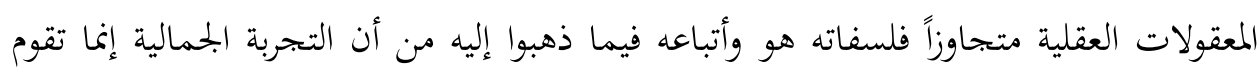
بين الإرادة الأخلاقية وبين عالم الطبيعة، وبالتالي يظهر هيجل تفوقه على مثالية كانط النقدية

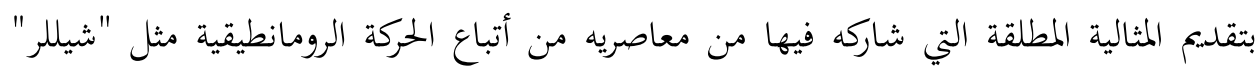

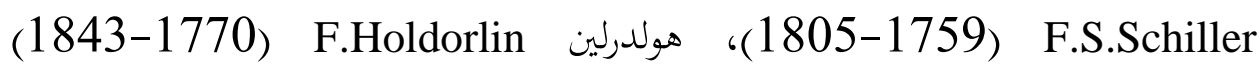
وشلنج كما كان للثورة الفرنسية دور فعال ومؤثر على كافة الأصعدة سواءً السياسية أو الثقافية وكل مظاهر الحياة وكافة شرائح البحتمع بدءًا من رجل الشارع وحتى أعلى قمة الهرم

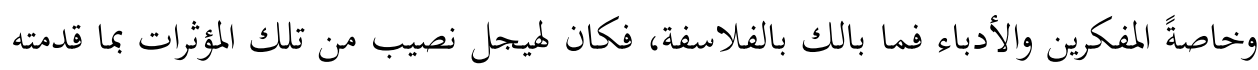

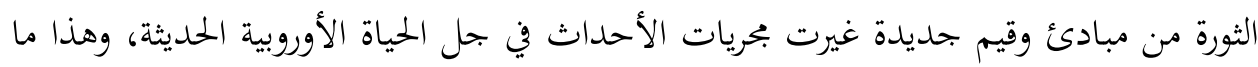
دعى هيجل إلى تناول مشكلة مصير الإنسان ومعاني وجوده مثلما ظهر لاحقاً في الفلسفات

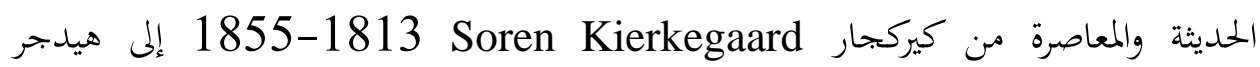
1980-1905 J.P.Sartre 1989-1889 Martin Heidegger Albert Camus ولم يخف هيجل إعجابه وتأثره بحضارة الإغريق القديمة وما تحويه من نظام سياسي

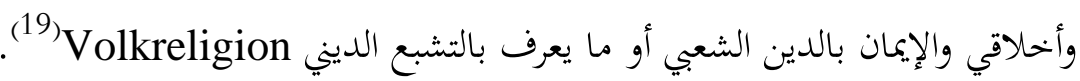


ولعل ما يميز العصر الحديث في هذا الشأن هو ظهور فلسفات واتبحاهات فردية

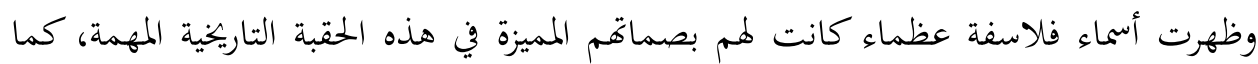

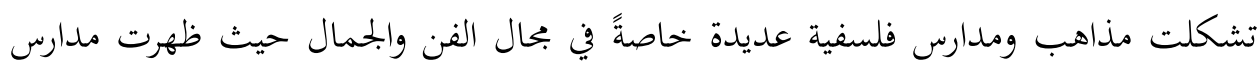
فنية مختلفة لكل منها خطوطها العريضة والدقيقة في تقييم ومعايرة مقاييس الجمال وتحديد الأنماط الفنية المتبعة في الأعمال الفنية وتقسيمها وفقاً لمعايير وشروط معينة، ولعل التقسيم الأبرز لتلك الاتحاهات أو المدارس هي المدرسة الكالاسيكية والمدرسة الرومانطقية والمدرسة الواقعية The Classical School - The Romantic School - The Realism

.School

أصبحت هذه المدارس من أهم ما يميز الفن وأسلوب الأعمال الفنية وتضم فئات من

الفنانين والفلاسفة كل حسب أسلوبه ومنهجه.

وقد تأثر هيجل بشكل مباشر بالحركة الرومانتيكية التي اهتمت بالتاريخ واعتباره جزءًا

من عملية الإبداع الفني؛ لكوها من أهم الاتحاهات التي تعتبر أساسية في تكوين فلسفة تاريخ باتيخ الفن والتي استلهم هيجل من خلالها رؤيته الخاصة به حول تاريخ الفن وتطوره (20).

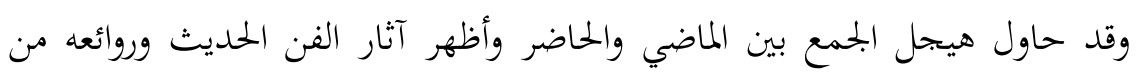

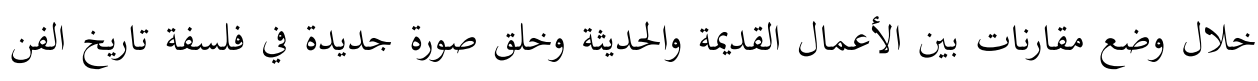
وتطوره.

وإذا ما نظرنا إلى فلسفة هيجل من هذا الجانب بند أنه قدم مفاهيم مختلفة عن تاريخ

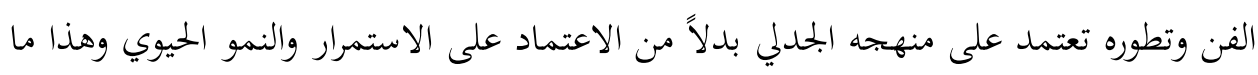
عرضه في كتابه عن الاستطيقا ويحمل عنوان "تطور المثال في الأشكال الخاصة من الجمال

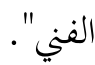

كما قدم نظريته في الفن وهي ذات طابع جدلي تحوي ثلاثة محاور رئيسية وهي الموضوع والنقيض والمركب وأصبح الطابع الجحلي أو التاريخية الجحلية هي ما يميز فلسفته الجمالية ويظل الفيلسوف "جيامباتيسا فيكو" 1668-1744 Giambattisa Vico هو من قدم 
المبادرة الأولى لهذا التصور الجلدي ولكن يظل هيجل هو صاحب التأثير المميز على الفن التشكيلي إبان عصره(21). يقدم هيجل تفسيراً فلسفياً لتاريخ الفن على أساس من فلسفته في تحقيق الفكرة وهذا

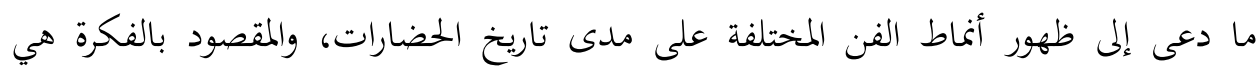
المضمون الذي يتم تجسيده أو تشكيله على هيئة أشياء حسية يمكن إدراكها سواءُ كانت مرئية

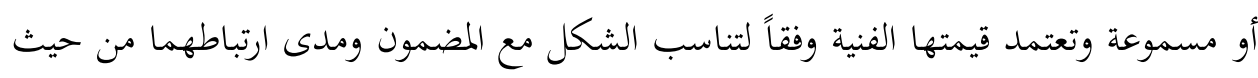
عمق الفكرة وجودة الأثر الفني لأن كلاً منهما يكمل الآخر. وبالتالي قد تخرج أعمال لا ترقى إلى المستوى الفني المرجو منها عندما يطغى الشكل على الفكرة أو في حالة عدم وجود تناسب أو انسجام ما بين الشكل والمضمون أو طغيان أحدهما على الآخر.

وقد لا تصل أنماط الفن إلى المثل الأعلى ومع ذلك لا يمكن بتحاهلها أو عدم الاكتراث

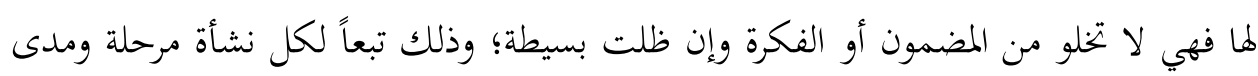

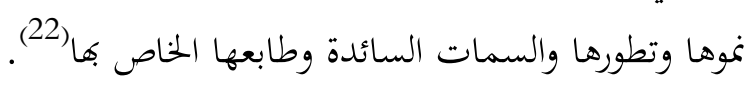
وتبعاً لذلك فإن هيجل قدم نظريته الفنية بتقسيم عصور الفن إلى ثلاثة مراحل أو وطاب أصناف محددة لأنماط الفن وهي فنون العصور البدائية والحضارات الشرقية ثم الفنون الإغريقية ومرحلة الفنون المعاصرة.

\section{تصنيفات هيجل للفنون الجميلة:}

قدم هيجل تصنيفه للفنون الجميلة وفق مذهبه وفلسفته المثالية وكانت من أبرز ما قدمه فلاسفة الجمال في القرن التاسع عشر بحيث جعل توافق ما بين العالم العقلي المطلق Absolute Mental World للجمال عبارة عن مركب مؤلف بين التصور العقلي المحرد وبين المادة الحسية للجمال.

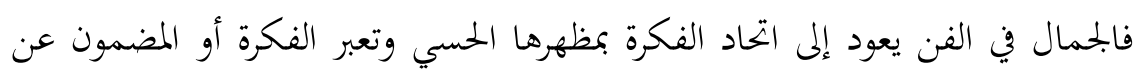

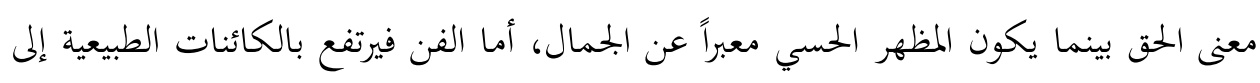




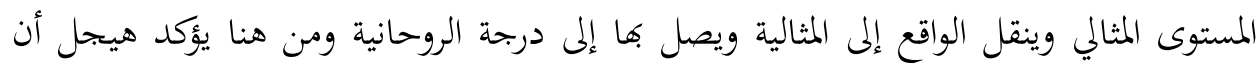

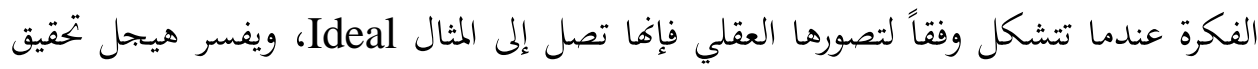

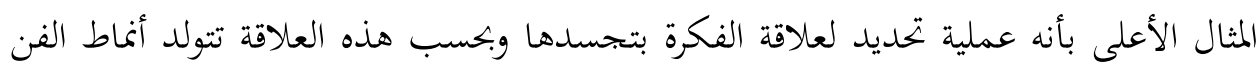

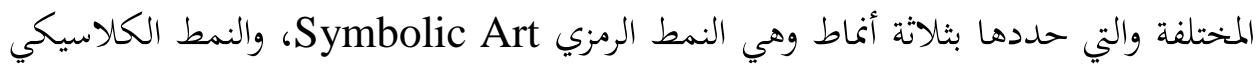
The Classical Art

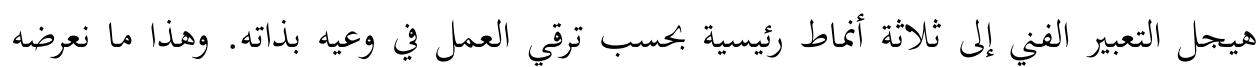

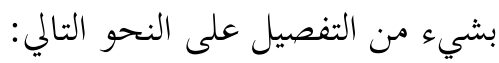

\section{Symbolic type of Art أولاً: النمط الرمزي للفن الفطيل}

ساد النمط الرمزي في الفن لفترة طويلة من تاريخ الفن منذ العصور البدائية والحضارات

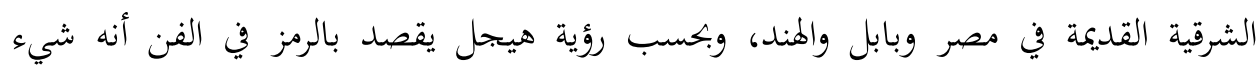

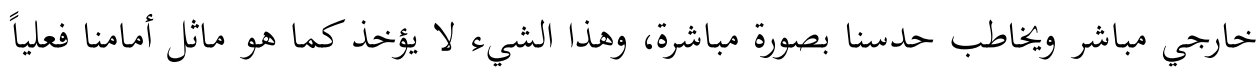

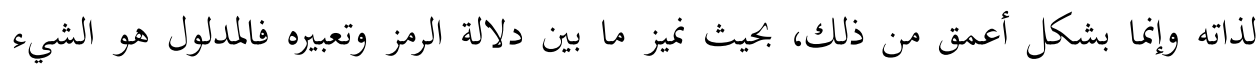

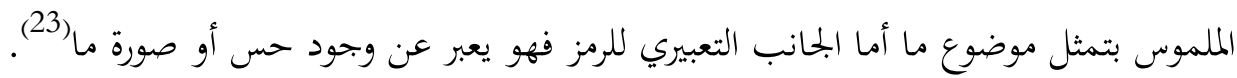
وبشكل عام قام هيجل بتحديد لمعنى مصطلح الرمزية Symbol واعتبره بمثل بداية

الفن من الناحية التاريخية ومن الناحية الفكرية كما ظهر واضحاً في الحضارات الشرقية.

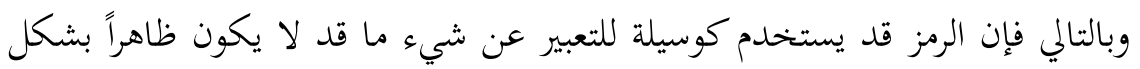

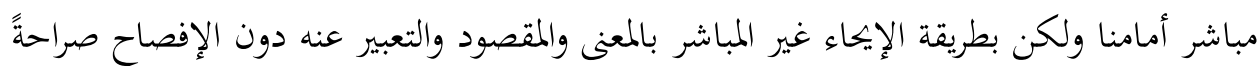

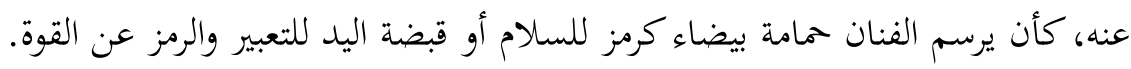

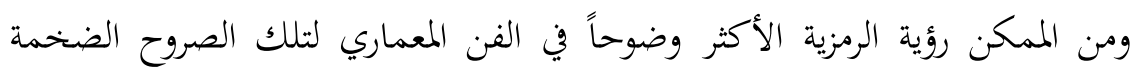

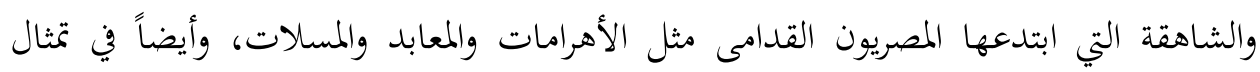

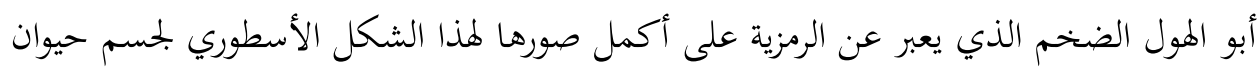
برأس بشرية ما يمثل لغزاً يرمز إلى جملة من المعتقدات والمعاني (24). 
وقد جعل هيجل من العمارة المصرية مثالاً لهذا النمط الرمزي للفن لما تعكسه من إيحاءات للألوهية وما تخفيه من أسرار عميقة وإن كانت لا تصل إلى المستوى المناسب في إظهار الجحانب الروحي وهذا يرجع لأن الشكل طغى على المضمون.

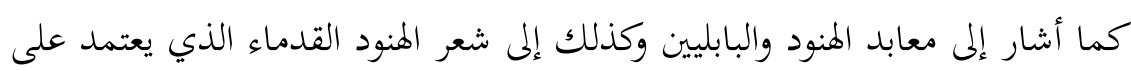
الرموز ويوحي بالجلال والروعة، ويؤكد هيجل أن المعنى الروحاني لا يتمثل بوضوح في الشكل الرمزي (25).

وبالتالي بند أن الفن الرمزي غير قادر على التعبير عن الأفكار الروحية وتمثيلها بشكل كامل وشامل، ولذلك يستخدم الرمز وسيلة للتعبير وإيصال فكرة معينة ويظل دوره الإيهاء لشيء ما، فالعمل الفني الرمزي هو شيء مادي ملموس ويظهر أمامنا يقوم بدور التجسيد

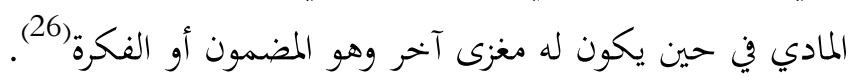
ويقدم هيجل تفسير عن مدلول الرمز واستعمالاته ويشرح ذلك بأنه كمثل استخدام

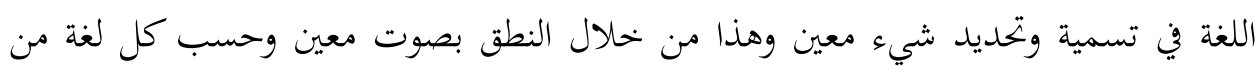
لغات العالم المختلفة، وهنا يظهر الاختلاف في النبرة والنطق لذات الشيء وغالباً يكون اللفظ ونظ

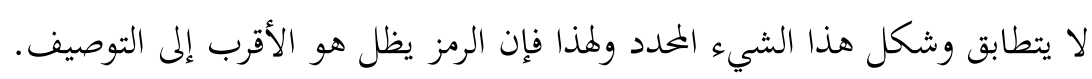

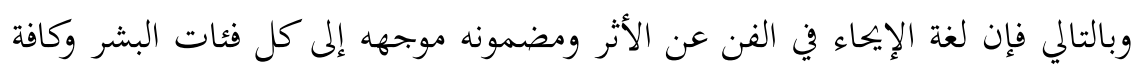
المحتمعات بمختلف أجناسهم ولغاقهم لأن لغة الفن واحدة وليست مقتصرة على فئة بعينها،

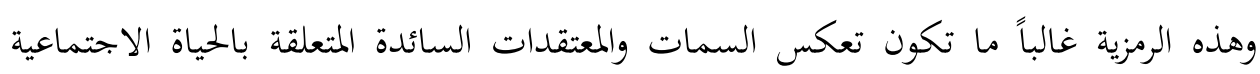
والمعتقدات الدينية والخرافات والأساطير.

\section{The Symbol and The Mythology العلاقة ما بين الرمز والأسطورة} لعل التساؤل المطروح في هذه العلاقة ما بين الرمز والأسطورة هو كيف يمكن الوصول إلى تفسير سليم ومنطقي لمغزى تلك الروايات والأشكال الأسطورية التي خلفتها المحتمعات

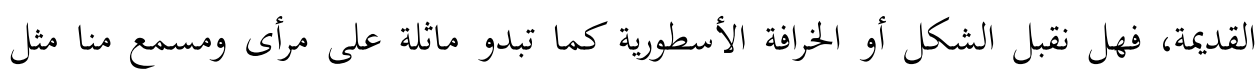


القصص والخرافات والروايات البطولية الخارقة، أم نلقي نظرة ثاقبة وبها عمق للنفاذ إلى المعنى الخفي من وراء هذا العمل الفني الأسطوري. لعل التساؤل المطروح قد يجد إجابات شافية فيما قدمه هيجل لتفسير تلك الظواهر الفنية وما ترمز له وطرح ابحاهين للبحث، الأول أن نقبل الأسطورة كما هي وكما تظهر للعيان دون البحث في مدلولها، والنظر إلى الأسطورة من وجهة النظر التاريخية التي تعتبر أن الميثولوجيا

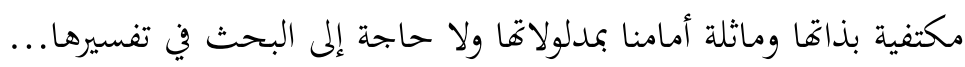

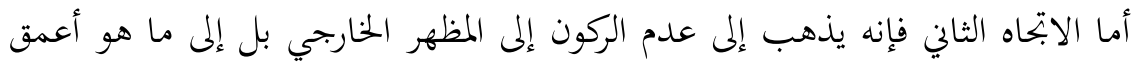

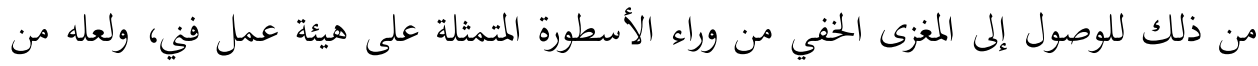

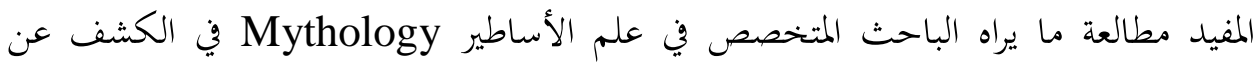
أسرارها وخفاياها وما تنطوي عليه من رموز ومعاني دفينة باعتبارها إبداعات فنية رمزية نابعة من ئن الروح... وفي هذا المجال يشير هيجل إلى العالم "فريدريك كروز" F.Greuzer 1858) كونه متخصص في الميثولوجيا وله دراسات عديدة في هذا البحال ومن أهمها كتاب "تأسيس علم الرموز" Issued of Symology وبين رؤيته بأن الأساطير ما هي إلا نتاج الفكر البشري الذي يتناول الآلهة وما تتطلبه من وسائل للعبادة والتقرب (27). وهنا يظهر العنصر الديني هو الدافع والمحفز للعقل البشري كي يبدع الأشكال الفنية

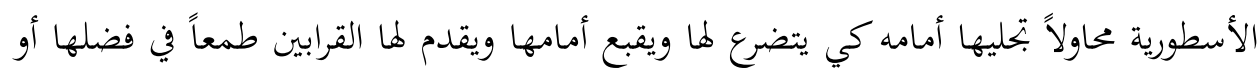
خوفاً منها أو لحمايته من أخطار الطبيعة وغضبها، مما جعل من الأسطورة وسيلة وأداة للدين. وسجل هيجل اعتراضه وعدم توافقه مع ما قدمه معاصره الفيلسوف فريدرش اشليجل F.V.Schlegel حيث أن لكل عمل أو شكل أسطوري فكرة عامة، ولكي نحصل على تفسير لمضمون هذا العمل يتوجب خلع الفكرة العمومية عن هذه الحالة الفنية وهذا ما يعارضه هيجل ويقول أننا بذلك سنقوم بخلع العمل الفني من قيمته وطابعه الخاص وينتج عنه الفصل بين الصورة وملولولها وهذا يؤدي إلى فقدان القيمة الفنية للعمل الفني في سبيل إيجاد الفكرة العامة(28). 
فهل نستنتج من ذلك وفقاً لرؤية اشليجل أن كل الأساطير ينبغي أن تفهم فهماً رمزياً من خلال البحث عن الرمز في كل عمل فني، وهذا أيضاً ما لا يقبله هيجل بحددًا ويقول بضرورة البحث إلى أي حد تصل درجة الرمزية في الشكل الفني أو بمعنى آخر مدى احتواء الشكل الفني على الرمزية ومدى عمقها.

ويدعي هيجل أن الفن في جانبه الموضوعي يتجه إلى الجانب الديني وهذا يظهر من

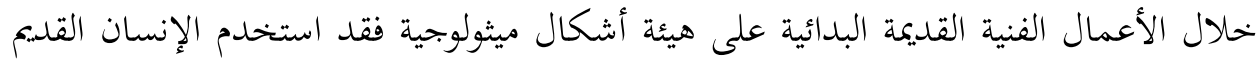

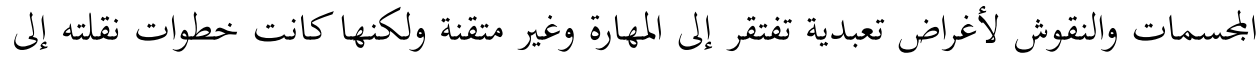

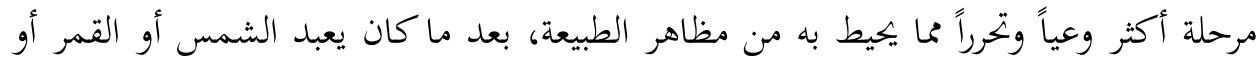
النار أدرك ما هو أبعد من ذلك وأصبح يبحث عن المطلق بمحاولته السيطرة على بكلى الطبيعة والوصول إلى الآلمة بواسطة أشكال من صنعه يتقرب بها وئ ويتعبدها.

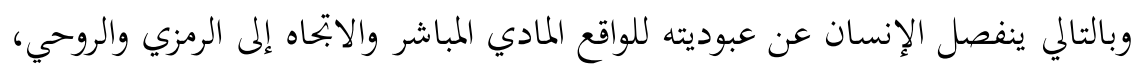
ومن خلال الأعمال الفنية الرمزية يصل إلى رمزية "الجليل" وهي الرمزية الواعية ومحاولة إدراك الوحدة ما بين الشكل والمضمون وهذا لا يتأثر إلا بانحسار الفن الرمزي وبروز الفن الكاسلاسيكي وهذا ما يدعونا إلى تناول هذه المرحلة التاريخية لظهور هذا الفن.

\section{النمط الكلاسيكي في الفن The Classical Type of Art}

يعتبر النمط الكلاسيكي في الفن امتدادًا وتطورًا لمرحلة الفن الرمزي بحسب

هيجل؛ حيث ابتعدت الأعمال الفنية عن الأشكال الغريبة والمحسمات القبيحة والغامضة التي اتخذها من الطبيعة المحيطة به والحيوانات والطيور المختلفة وانتقل إلى السمو والاتحاه إلى الأشكال الآدمية، مما يوحي بإدراك الروح لذاتما ومحاولة بتحيدها، وهذا ما عرف بفن النحت وتشييد التماثيل كما هو ملاحظ في فنون اليونان القديم حيث استطاعوا التعبير Sculpture ببراعة عن الروح الكلاسيكية التي جعلت هذا النمط الفني الأجدر في التعبير عن المثل الأعلى

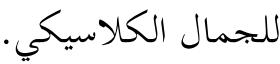


اشتهر أهل اليونان القديم بولعهم وتقديرهم للفن والفنانين ولعل هذا الاهتمام والوعي

انعكس على مظاهر الحياة بمختلف جوانبها الحضارية، واعتقدوا بوجود ربات الفنون بحيث يكون لكل نوع من الفنون ربة خاصة به وهي التي تلهم الفنان وتمنحه القدرة لإبداع الفن سواءً

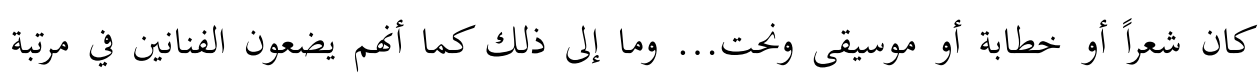
الأنبياء الملمهمين.

ولهذا ارتبط الفن الكلاسيكي بصفة خاصة باليونان القديم مثلما ارتبط الفن الرمزي

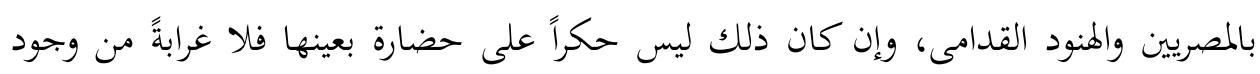

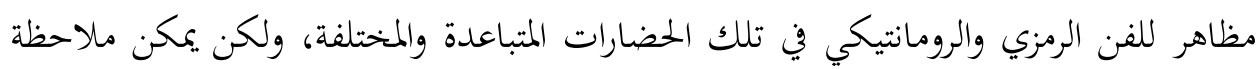

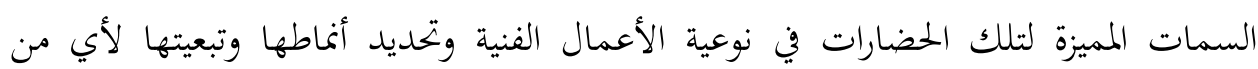
الفنون، وبالتالي فإن الأعمال التي يظهر فيها توافق ما بين الشكل والمضمون يمكن تصنيفها ضمن هذا النمط الكلاسيكي في الفن(29). هذا التطابق بين الشكل والمضمون يظهر جليَّا في الفن الإغريقي من خلال النحت

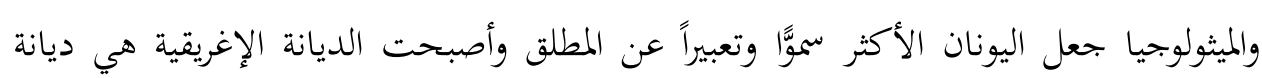
الفن أو الديانة الجمالية. قدم هيجل تميزاً ما بين الأعمال الفنية في المرحلة الرمزية التي تتسم بالضخامة والتصلب التبال وطغيان الشكل المفرط على المضمون في محاولة لتحقيق رمزية معينة، وتلك الأعمال الفنية

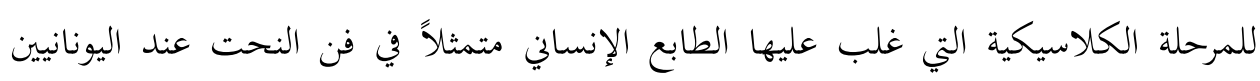

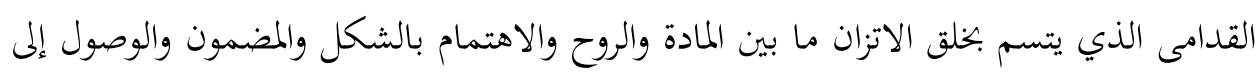
التمازج ما بين الرمزية والواقعية، وقد سبقهم إلى ذلك الحضارات الشرقية مثل الفرعونية والهندوسية. ولكن الروح لا تستكن والعقل لا يهدأ إذ لا حدود لطموحات الجنس البشري نحو

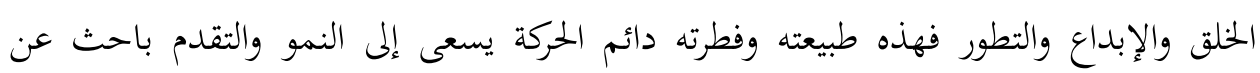

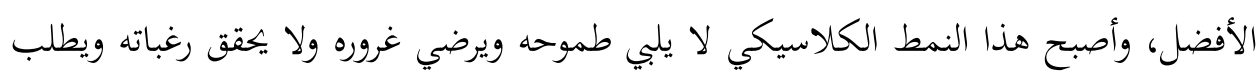


ما هو أكثر من ذلك وهذا ما جعله يتجه إلى البحث في المطلق في ما وراء الطبيعة من خلال الأعمال الفنية في محاولة لبلوغ المثالية والآفاق العليا، وهذا ما ذإل ظهر لاحقاً في مرحلة الفن الرومانطيقي.

\section{النمط الرومانتيكي في الفن The Romantic Type of Art:}

لعل هيجل وجد ضالثه في هذا النمط المتطور من الفن الذي يتجه إلى المضمون

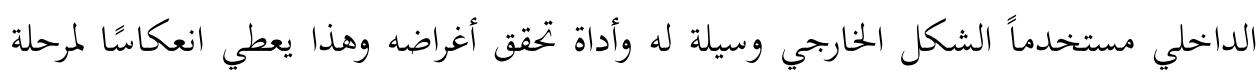

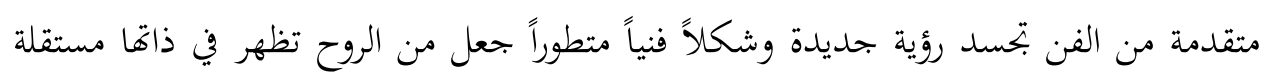

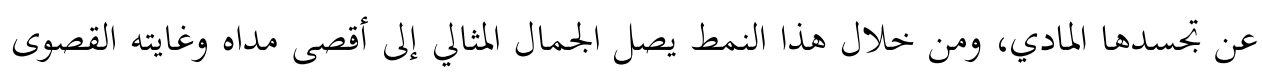

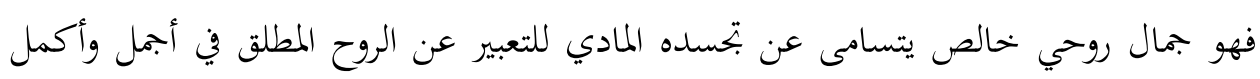
صورة. وبحسب رؤية هيجل فإنه في هذه المرحلة يتحقق للفن التحرر من قيود الواقع نحو

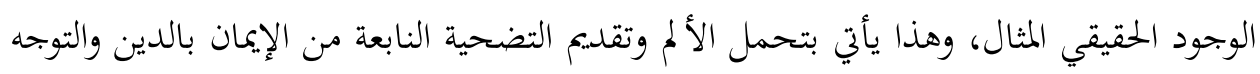

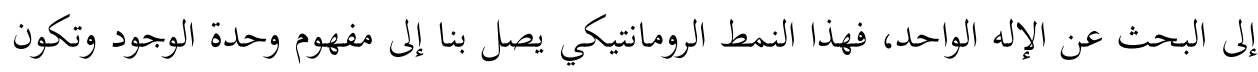
مهمة الفن استخدام الحس الخارجي للتعبير عن الروح الداخلي وظهور الطابع الفردي المستقل

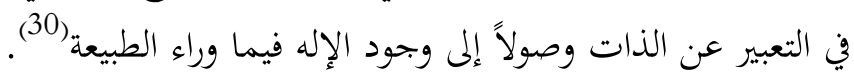

ولكي يصل إلى مستوى الألوهية يتوجب التخلص من الجانب الفيزيقي المادي من

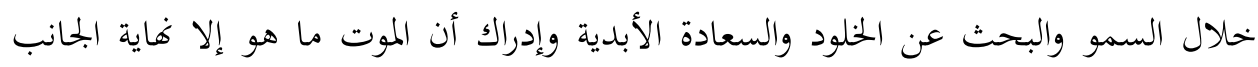
المادي وبدايةً للعا لم الروحي الأزلي.

وهذا على غرار رؤية أفلاطون للوجود المادي بأنه ظلال للعالم المثالي "الأنطولوجي" Ontology بالجسد وتلتحق بعالمها الحقيقي الأصل، ولكنها تحاول التطلع إلى عالمها من خلال ما تراه من

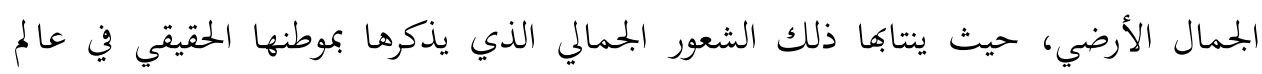
المثل (31). 
هذا التطور للروح الذي يصل إلى السمو على ذاته هو المبدأ الذي يقوم عليه الفن

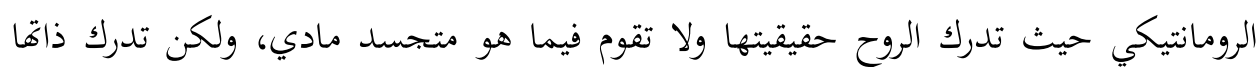

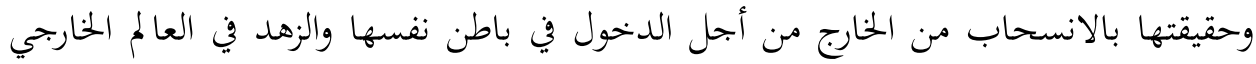

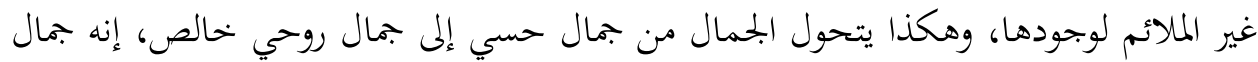
الذاتية اللامتناهية والروحية في ذاتما.

قدم هيجل تفسيره في تحليل وتوصيف الفن الرومانتيكي من خلال المظاهر الماثلة

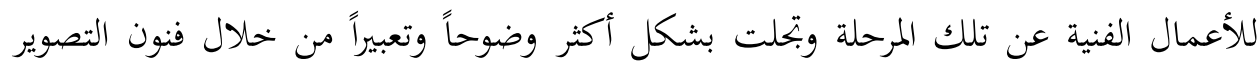

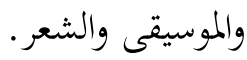

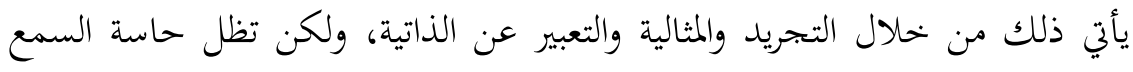

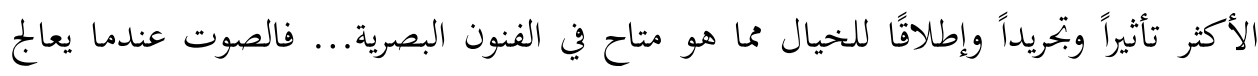

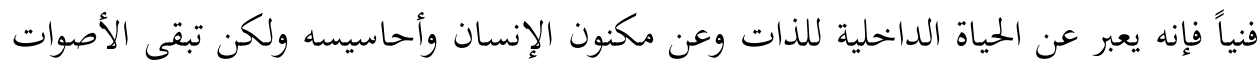
التي لا تمر بتلك الحالة الفنية بجرد أصوات خالية ولا تؤلف عملاً فنياً. ويرى هيجل أن فن الشعر هو الأعلى والأسمى في التعبير عن الروحانية ومن خلاله

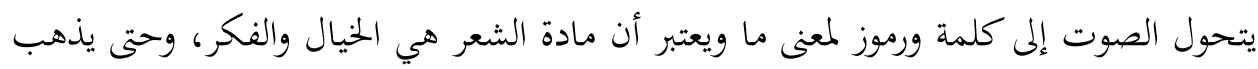

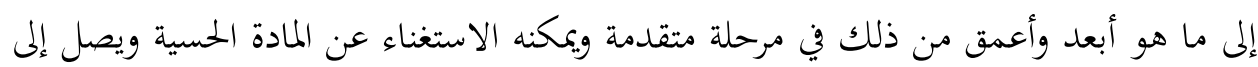
فن النثر المعبر عن الأفكار محل الشعر الخيالي (32).

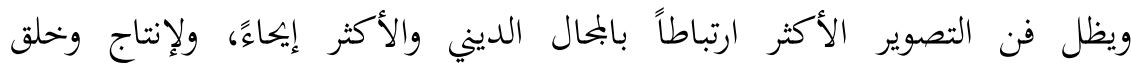

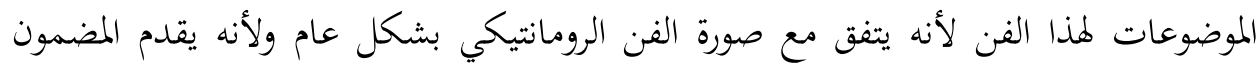

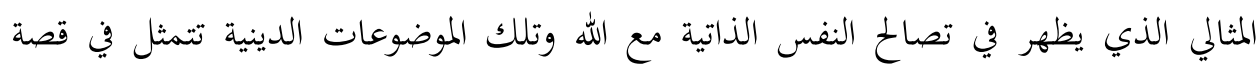
الفداء والتضحية وصور الحب المختلفة والحب الإلمي.

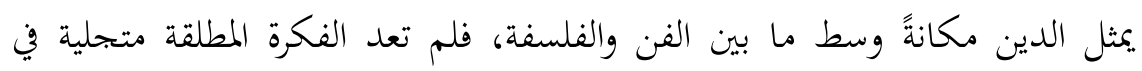
صورة موضوع من موضوعات الحس، وإن كانت لا تزال لا تفهم من ذلك في صورة عقلية

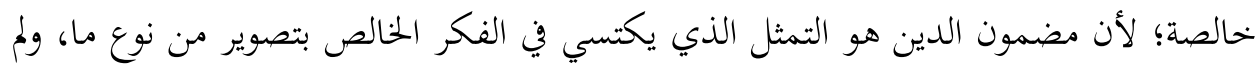


يرفض هيجل الدين من حيث إنه بحرد أوهام شعبية فهو يرى فيه بحليات فعلية للمطلق الذي يعبر عن الحقيقة بصورة كافية مثلما يستطيع العقل العادي أن يفهمها. ويجد في الديانة المسيحية التي يصفها بالديانة المطلقة التمثل الأكثر كفاية للحقيقة الممكنة للدين، حيث يعتبر الله هو المنطق والمسيح هو عالم الطبيعة وتكون روح القدس متجسداً في الكنسية(33). وبحد الكنيسة القوطية Gothic عبارة عن نطاق يلم الجماعة المسيحية التي تنطوي على نفسها وتخلو إلى ذاتا وتستغرق في التأمل والتسامي وصولاً إلى العبادة الخالصة والانعزال عن العالم الخارجي وبالتالي فإن العمارة القوطية تعبر عن الاختلاء بالنفس.

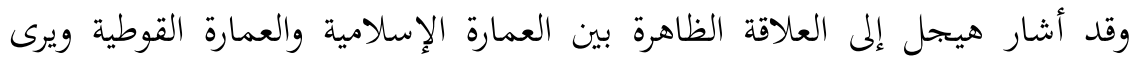
وجود فروق جوهرية تفصل بينهما، وتصميم المباني وفقاً لطريقة العبادة المتبعة حيث أن وضعية العبادة وطقوسها في الإسلام تختلف عن العبادة المسيحية. وتتميز العمارة الإسلامية بالنقوش والزخارف المقتبسة عن النباتات والأشكال الهندسية والأقواس والخط العربي وأيضاً ما اقتبسوه من فن العمارة الرومانية مع استبعاد للأشكال والمحسمات للكائنات الحية، حيث هناك رأى لدى أغلب المذاهب الإسلامية لا يجيزون تصوير الإنسان أو أي كائن حي آخر. وهذا التشدد في مواجهة الأعمال الفنية قد لا يدعو إلى الدهشة خحاصةً في فنون التصوير وأعمال النحت والتماثيل، فقد لازم ذلك جلّ الأديان وواجه الرفض والكراهية والتحريم مثل ما حدث مع الديانة اليهودية من قبل والديانة المسيحية فيما بعد ولكن بمرور الزمن تطور

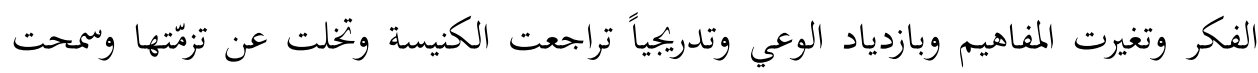

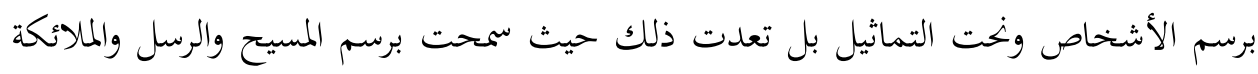

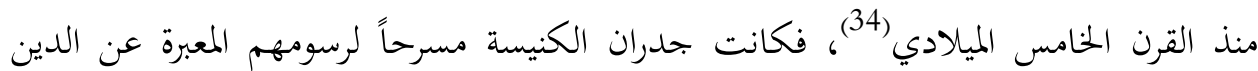

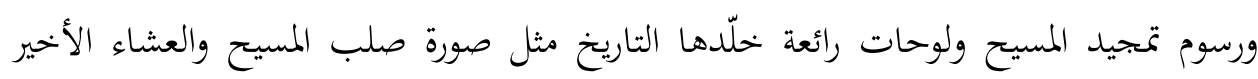
والخطيئة، ولكنها لم تصل بعد إلى المثل الأعلى والمطلق. 
هذا العجز عن تصوير المثل الأعلى في المادة هو أصل الدين وموضوع الدين المثل

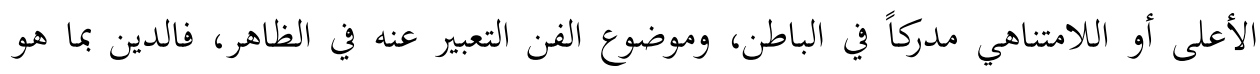

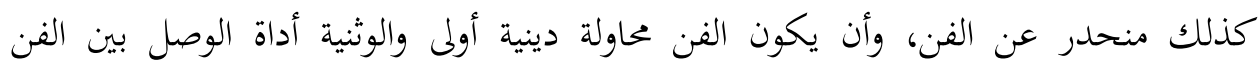
والدين(35) فهو يرى في الدين تجليات فعلية للمطلق، الذي يعبر عن الحقيقة بصورة كافية مثلما يستطيع العقل العادي أن يفهمها. وفي هذا الجانب فإن رؤية هيجل لاقت نقداً ومعارضة شديدة من أشهر أتباعه

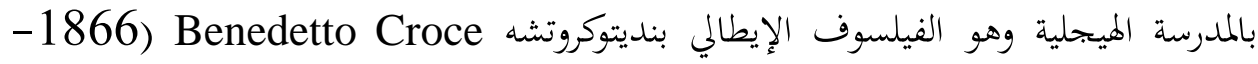

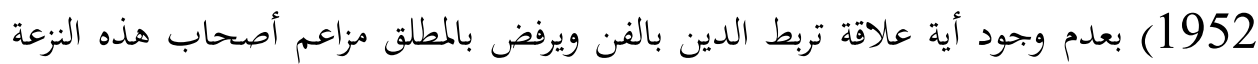

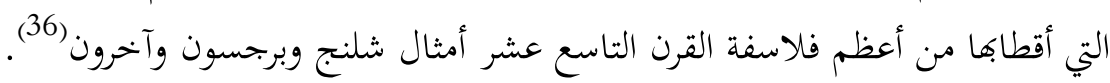

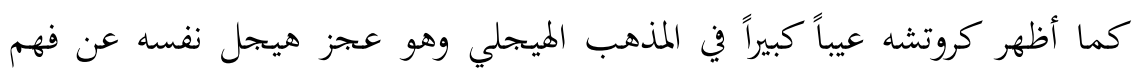

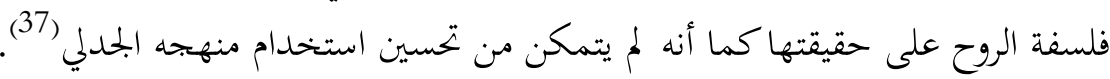
فالفن عند هيجل نتاج الفكر كما هو الحال في المنطق وفلسفة الروح، فلا توجد مند معرفة

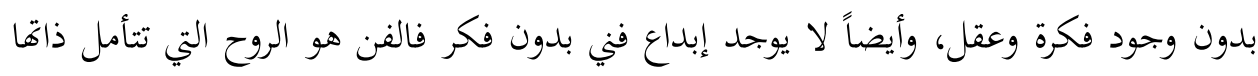

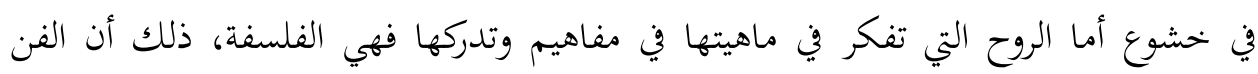

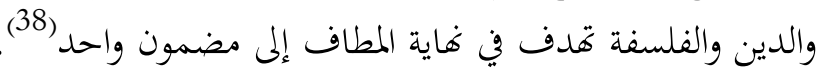

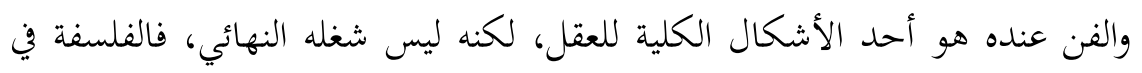
رأيه هي الشكل النهائي للعقل، وغايته القصوى، وما الفن سوى خطوة سابقة في طريق العقل نخو الحقيقة (39). ويختم هيجل الحركة الرومانتيكية في جانبها الفلسفي، وعلمنا بطريقة أكثر عقلانية أن

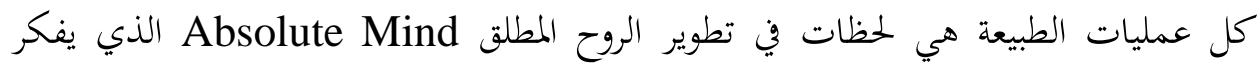
بعملية منطقية فلابد من تفسير التاريخ البشري والفن والعلم والدين وفقاً لمبادئ روحية وموضوعية وعقلية. الخاتمة:

الجمال الفني هو وحده الذي يكفل التوحد بين الفكرة والشكل لأنه ينبع من الروح الإنسانية وليست الرغبة هي ما يربط الفرد بالعمل الفني؛ لأن الحكم الجمالي موضوع للعقل 
والتأمل غير أن التأمل الجمالي يختلف عن التأمل في العالم لأن التأمل الفني حسّي والتأمل في العلم جوهري.

ويرجع تقسيم الفن عبر مراحل إلى اعتبار العمل الفني تجسيداً لاتحاد الفكرة بمظهرها

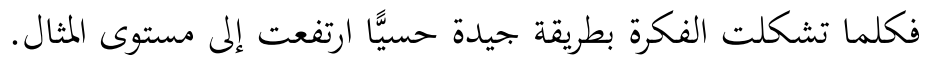

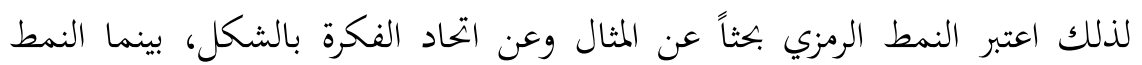

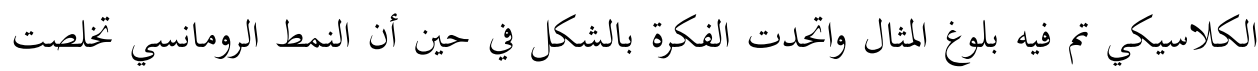

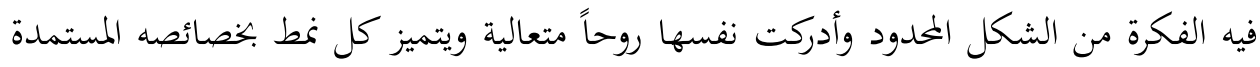
من ميتافيزيقا هيجل في علاقة الفكرة بتجسدها الخارجي.

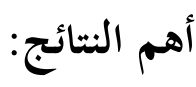

- - عرض رؤية جديدة ومغايرة لما سبق طرحه لأهم المحاور في فلسفة هيجل الجمالية. - تقديم هذه اللمحة عن دراسات هيجل في الفن بمثابة موجز لمعرفة تاريخ الفنون الأوروبية.

- التعرف على العلاقة الجدلية ما بين الفن والدين والفلسفة وفقاً لرؤية هيجل.

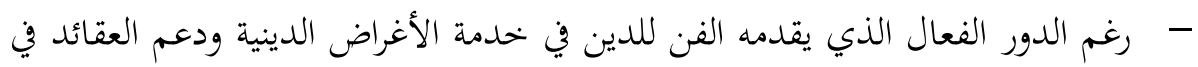

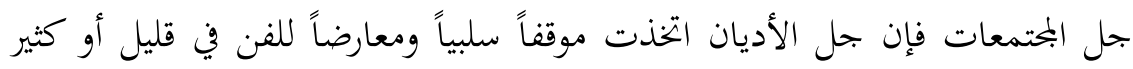
وصلت إلى حد التحريم القطعي. - - عرض رؤية هيجل المثالية في إشكالية الشكل والمضمون في الفن من الأهمية بمكان وسط الجدل والاختلاف القائم فيما بين الفلاسفة على مرّ التاريخ.

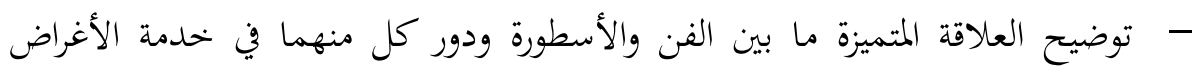
الدينية. 


\section{الهوامش}

(") المثالية المطلقة: الواقع كله متضمن داخل نسق واحد مكتمل، يعرفه عقل يشمل كل شيء، ويسمى

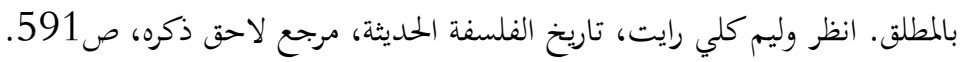

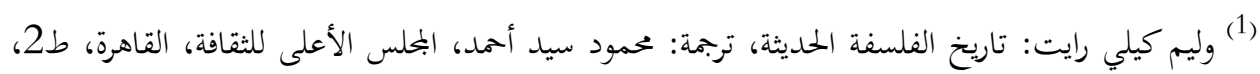
ص 309.

(2) يوسف كرم: تاريخ الفلسفة الحديثة، دار القلم، بيروت، ط1، ص274. (3) محمد علي أبوريان: فلسفة الجمال ونشأة الفنون الجميلة، دار المعارف الجمالية، الإسكندرية، ص43. (4) راوية عبدالمنعم عباس: فلسفة الجمال وتاريخ الوعي الجمالي، دار المعرفة للنشر، الإسكندرية، 1991م، ص 386. (5) (5مد علي أبوريان، المرجع السابق، ص44. (6) مراد وهبة: قضية علم الجمال، دار الثقافة الجديدة، ط1، 1996، ص44. (7) بحاهد عبدالمنعم بحاهد: دراسات في علم الجمال، عالم الكتب، بيروت، ط2، 1986، 1980، ص20.

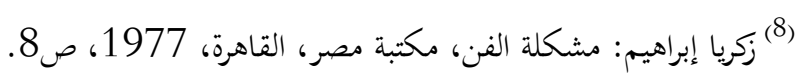

(9) حسين علي: فلسفة الفن رؤية جديدة، الدار العربية السعودية للطباعة، القاهرة، ط1، 2005، ص24. (") اعتقد اليونانيون قديماً بعدد من الآلة وكان من بينها الإله بروميثوس وقد تخصص في خلق البشر وتزويدهم http://greekmethology1.blogspot.com بمتطلبات الحياة.

(10) أميرة حلمي مطر: فلسفة الجمال، دار الثقافة للنشر والتوزيع، القاهرة، 1983، ط2، ص58. (") الديثرامب: يقصد ها الترتيل والإنشاء لقصيدة أو مرثية وترانيم تمثل جزئًاً من المسرح الإغريقي

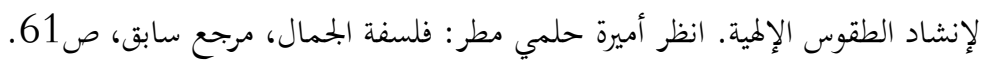

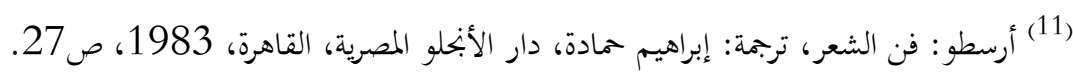

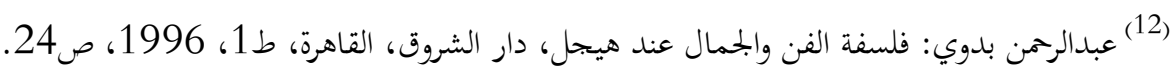


(13) فتحي إبراهيم: معجم المصطلحات الأدبية، الموسوعة العربية للناشرين المتحدين، تونس، ط1، 1996، ص 313.

(14) Zink.S: The Moral Effect of Art, in "vivas, E. \& Krieger. M" Eds of The Problems of Aesthetics Holt, Rinhart and Winston. N.Y. 1953 , P.549.

(15) بروم ستوليتز: النقد الفني دراسة جمالية وفلسفية، ترجمة فؤاد زكريا، الميئة المصرية العامة للكتاب، القاهرة، 156

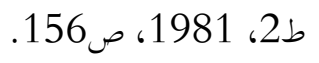

(16) أمير: حلمي مطر، فلسفة الجمال، دار الثقافة للنشر والتوزيع، القاهرة، ط2، 1983، ص112.

(17) Bertrand Russel: History of Western Philosophy. Touch Stone Book, Published by Simon and Schuster. U.S.A, 1972. P.371.

$$
\begin{aligned}
& \text { (18) أمير حلمي مطر، فلسفة الجمال، مرجع سابق، ص111. } \\
& \text { (19) المرجع نفسه، ص112. (19) }
\end{aligned}
$$

(20) جاتيان بيكون: علم الجمال والتاريخ، ترجمة: فوزي سمعان، مطبوعات اليونيسكو، 1970، ص55.

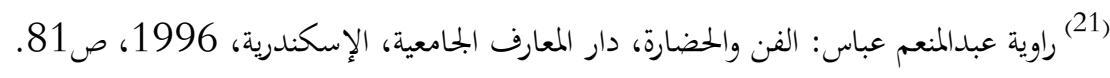

$$
\text { (22) أميرة حلمي مطر، فلسفة الفن، مرجع سابق، ص116. }
$$

(23) رمضان بسطويسي: جماليات الفنون وفلسفة تاريخ الفن عند هيجل، المؤسسة الجامعية للدراسات والنشر،

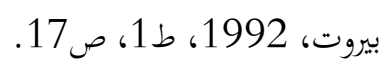

$$
\begin{aligned}
& \text { (24) أميرة حلمي مطر: مقدمة في علم الجمال، مرجع سابق، ص126. }
\end{aligned}
$$

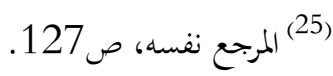

(26) ولتر ستيس: فلسفة هيجل، ترجمة إمام عبدالفتاح إمام، دار الثقافة، القاهرة، 1980، ص634.

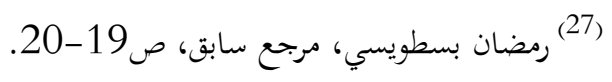




$$
\begin{aligned}
& \text { (28) (المرجع نفسه، ص21. } \\
& \text { (29) ولترسيتس، فلسفة هيجل، مرجع سابق، ص646. } \\
& \text { (30) رمضان بسطاويسي: جماليات الفنون، مرجع سابق، ص72. }
\end{aligned}
$$

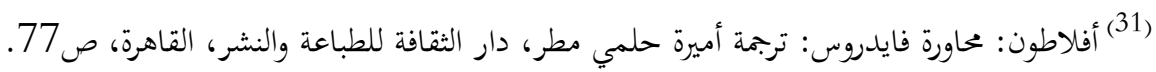

$$
\begin{aligned}
& \text { (32) أميرة حلمي مطر: فلسفة الفن، مرجع سابق، ص124. } \\
& \text { (33) وليم كلي رايت، مرجع سابق، ص337. }
\end{aligned}
$$

(34) أبو صالح الألفي: الموجز في تاريخ الفن، دار فضة مصر للطباعة والنشر، الفجالة، القاهرة، ص134.

$$
\text { (35) يوسف كرم: تاريخ الفلسفة الحديثة، مرجع سابق، ص285. }
$$

(36) بنديتو كروتشه: البممل في فلسفة الفن، ترجمة سامي الدروبي، دار الفكر العربي، القاهرة، ط1، 1947، ص36.

(37) مارتن هيجر: نداء الحقيقة، ترجمة عبدالغفار مكاوي، دار الثقافة للطباعة والنشر، القاهرة، 1977،

(38) عبدالمعطي محمد علي: فلسفة الفن رؤية جديدة، دار النهضة العربية، بيروت، 1985، ص46.

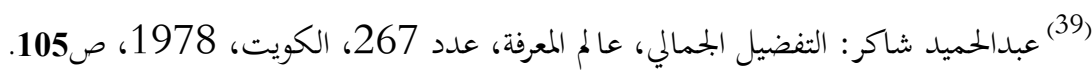

